\title{
A functional myo-inositol catabolism pathway is essential for rhizopine utilization by Sinorhizobium meliloti
}

\author{
Mark P. Galbraith, ${ }^{\dagger} \dagger$ Szi Fei Feng, ${ }^{1}$ James Borneman, ${ }^{2} \neq$ Eric W. Triplett, ${ }^{2}$ \\ Frans J. de Bruijn ${ }^{3}$ and Silvia Rossbach ${ }^{1}$
}

Author for correspondence: Silvia Rossbach. Tel: +1 616387 5868. Fax : +16163872849.

e-mail: Silvia.Rossbach@wmich.edu

1 Department of Biological Sciences, Western

Michigan University,

Kalamazoo, MI 49008, USA

2 Department of Agronomy and Center for the Study of Nitrogen Fixation, University of WisconsinMadison, Madison, WI 53706, USA

3 MSU-DOE Plant Research Laboratory, Department of Microbiology, NSF Center for Microbial Ecology, Michigan State University, East Lansing, MI 48824, USA

\begin{abstract}
Rhizopine (L-3-0-methyl-scyllo-inosamine) is a symbiosis-specific compound found in alfalfa nodules induced by specific Sinorhizobium meliloti strains. It has been postulated that rhizobial strains able to synthesize and catabolize rhizopine gain a competitive advantage in the rhizosphere. The pathway of rhizopine degradation is analysed here. Since rhizopine is an inositol derivative, it was tested whether inositol catabolism is involved in rhizopine utilization. A genetic locus required for the catabolism of inositol as sole carbon source was cloned from S. meliloti. This locus was delimited by transposon Tn5 mutagenesis and its DNA sequence was determined. Based on DNA similarity studies and enzyme assays, this genetic region was shown to encode an S. meliloti myo-inositol dehydrogenase. Strains that harboured a mutation in the myo-inositol dehydrogenase gene (idhA) did not display myoinositol dehydrogenase activity, were unable to utilize myo-inositol as sole carbon/energy source, and were unable to catabolize rhizopine. Thus, myoinositol dehydrogenase activity is essential for rhizopine utilization in S. meliloti.
\end{abstract}

Keywords: Sinorbizobium meliloti, rhizopine catabolism, inositol catabolism, idhA, myo-inositol dehydrogenase

\section{INTRODUCTION}

Rhizopines are known to be nutritional mediators, and have been shown to play a role in nitrogen-fixing symbiotic associations between members of the Rhizobiaceae and legume plants (Murphy \& Saint, 1992). One specific rhizopine, the inositol compound L-3-O-methylscyllo-inosamine (3-O-MSI), is synthesized by Sinorhizobium meliloti strain L5-30 in nodules of its host plant, Medicago sativa (alfalfa). This strain, L5-30, is able not only to synthesize the rhizopine in nodules, but also to degrade and utilize rhizopine under free-living conditions (Murphy et al., 1987; Rossbach et al., 1994a). It has been postulated that the rhizopine represents a nutrient source for bacterial strains that possess the

\footnotetext{
†Present address: Merck \& Co., WP 77T, Sumneytown Pike, West Point, PA 19486, USA.

¥Present address: Department of Plant Pathology, University of California, Riverside, CA 92521, USA.

Abbreviation: 3-O-MSI, L-3-O-methyl-scyllo-inosamine.
}

The GenBank accession number for the sequence reported in this paper is AF059313. ability to degrade it. In fact, it has been reported that bacterial strains which are able to synthesize and utilize 3-O-MSI have a fitness advantage and are better able to nodulate their host plant, alfalfa (Gordon et al., 1996).

Interestingly, the occurrence of rhizopine synthesis and catabolism genes is rare among different strains of Rhizobiaceae. Only three S. meliloti strains of 50 worldwide isolates tested were found to be able to synthesize and catabolize rhizopine and to possess the appropriate rhizopine synthesis (mos) and catabolism (moc) genes (Rossbach et al., 1995b). In another study, out of 300 strains tested, only $12 \mathrm{~S}$. meliloti and nine Rhizobium leguminosarum bv. viciae strains were shown to be able to catabolize and synthesize rhizopine (Wexler et al., 1995). Based on the availability of cloned moc and mos genes, we are pursuing two goals. First, we are constructing a selectable marker cassette based on the moc genes, since the presence of the rhizopine catabolism genes in an organism endows it with the ability to utilize 3-O-MSI as sole nitrogen and carbon source. Second, by constructing transgenic plants expressing the mos genes and secreting rhizopine we will 
attempt to create so-called 'biased rhizospheres', in which beneficial soil bacteria, harbouring the moc genes, may gain a competitive advantage and thus be selectively enriched in the rhizosphere (Rossbach et al., 1995b).

A detailed knowledge of the structure and expression of the rhizopine synthesis and catabolism genes is required for both these projects. mos genes involved in the synthesis of 3-O-MSI and moc genes involved in catabolism and utilization of rhizopine have been cloned from S. meliloti strain L5-30 and characterized in detail (Murphy et al., 1987, 1988, 1993; Rossbach et al., 1994a). Determination of the DNA sequence of the moc locus, coupled to $\operatorname{Tn} 5$ mutagenesis, revealed that out of the six ORFs present at this locus four are essential for rhizopine catabolism, mocABR and mocC (Rossbach $e t$ al., 1994a). Comparison of the deduced protein sequences with sequences in the databases allowed a prediction of their putative roles in rhizopine catabolism. MocB appears to be a periplasmic binding protein, probably facilitating the transport of rhizopine into the cell, whereas MocR is a regulatory protein, containing a DNA-binding motif. It is suspected that MocA and MocC are enzymes involved in the degradation of rhizopine (Rossbach et al., 1994a). MocA appears to be a dehydrogenase and both MocA and $\mathrm{MocC}$ proteins display similarities to proteins encoded by genes located in the myo-inositol catabolism operon of Bacillus subtilis (Yoshida et al., 1997).

The rhizopine 3-O-MSI is an inositol derivative. myoInositol is a common and essential compound present in plants (Loewus, 1990). A variety of soil- and plantassociated bacteria have been described that possess the ability to degrade myo-inositol, including Aerobacter aerogenes (now Klebsiella pneumoniae), $R$. leguminosarum bv. viciae, B. subtilis and $S$. meliloti (Anderson \& Magasanik, 1971a, b; Berman \& Magasanik, 1966a, b; Bosworth et al., 1994; Fujita et al., 1991; Loewus, 1990; Poole et al., 1994). In K. pneumoniae and $R$. leguminosarum bv. viciae, the pathway of inositol degradation has been shown to involve the enzymes myo-inositol dehydrogenase and 2keto-myo-inositol dehydratase (Berman \& Magasanik, 1966a; Poole et al., 1994). The genes involved in myoinositol degradation have been cloned and sequenced from the Gram-positive bacterium B. subtilis (Fujita et al., 1991; Yoshida et al., 1994, 1997).

Mutant strains of $S$. meliloti that are not able to use myo-inositol as sole carbon source have been described (Bosworth et al., 1994). These S. meliloti mutant strains carry the interposon $\Omega$ in a genetic locus responsible for inositol catabolism. These strains were among the first genetically modified micro-organisms released in field experiments, since the inositol locus was used as the integration site for genes that increase the nitrogenfixation capacity (nifA, dctABD; Bosworth et al., 1994; Scupham et al., 1996).

We hypothesized that inositol catabolism is involved in rhizopine degradation, and we tested this hypothesis by analysing the $S$. meliloti mutant strains that are unable to grow on myo-inositol as sole carbon source. These $S$. meliloti mutant strains were shown to carry an insertion in a myo-inositol dehydrogenase gene and to lack myoinositol dehydrogenase activity. The locus encoding myo-inositol dehydrogenase was cloned and delimited via $\operatorname{Tn} 5$ mutagenesis. The myo-inositol dehydrogenase gene was the only gene in this locus essential for the utilization of myo-inositol as sole carbon source. Moreover, $S$. meliloti mutant strains with an insertion in the myo-inositol dehydrogenase gene were found to be unable to utilize rhizopine. Thus, we conclude that a functional myo-inositol catabolism pathway is essential for the ability to utilize rhizopine.

\section{METHODS}

Bacteria, plasmids and growth conditions. The bacterial strains and plasmids used in this study are described in Table 1. Escherichia coli strains were grown in LB with appropriate antibiotics (Miller, 1992). Minimal medium for E. coli was M9 (Miller, 1992). Rich medium for S. meliloti was TY (Beringer, 1974), and as minimal medium either GTS (Kiss et al., 1979) or the minimal M medium described by Rossbach et al. (1994a) was used. In minimal $M$ medium the carbon source was glucose (final concentration $0.25 \%$ ) and the nitrogen source was potassium nitrate (final concentration $0 \cdot 1 \%$ ). S. meliloti strains were grown at $28^{\circ} \mathrm{C}$.

Molecular techniques. Chromosomal and plasmid DNA isolation procedures were carried out essentially as described by Ausubel et al. (1992) and Sambrook et al. (1989). DNA probes were labelled with digoxigenin-11-dUTP of the DIG DNA Labelling kit and detected with the DIG Luminescent Detection kit, both from Boehringer Mannheim. The construction of the cosmid clone bank of $S$. meliloti strain 1021 used in this work was described previously (de Bruijn et al., 1989). Triparental conjugations, transposon $\operatorname{Tn} 5$ mutagenesis of plasmid pMG1000, and gene replacement techniques were carried out as described by de Bruijn \& Rossbach (1994). Gene replacements were verified by correct marker exchange and for mutant strains L56, \#56, \#105 and \#113 by Southern blotting and hybridization with the wild-type region. Manual DNA sequencing was carried out with the T7 Sequenase 7 . Deaza-dGTP sequencing kit and radioactive $\left.{ }^{35} S\right] \mathrm{dATP} \alpha \mathrm{S}$ (Amersham). Oligonucleotides were purchased from Only DNA. For DNA sequence analysis the following computer programs were used: IntelliGenetics Molecular Biology Software System 5.4, CodonUse 3.1 (Conrad Halling, University of Chicago, USA), SeqVu 1.0.1 (The Garvan Institute of Medical Research), BLAST programs (Altschul et al., 1990) and the programs BESTFIT, gap, PILEUP, peptidesort from the Wisconsin Package 9.1, Genetics Computer Group (GCG), Madison, WI, USA.

Enzyme assays. Precultures were inoculated 1:100 in 2.8 1 Fernbach flasks containing $250 \mathrm{ml}$ minimal medium with $0.2 \%$ succinate as carbon source and $0.02 \%$ myo-inositol as inducer. Mid-exponential-phase cultures were pelleted, washed with $40 \mathrm{mM}$ HEPES buffer $(\mathrm{pH} 7.0)$ and resuspended in $5 \mathrm{ml}$ buffer. Cells were disrupted with a Branson W185 sonicator at $50 \mathrm{~W}$ with three $10 \mathrm{~s}$ sonication periods. Cell debris was pelleted and the supernatant was used directly for enzyme assays. myo-Inositol dehydrogenase activity was determined as previously described by Poole et al. (1994). Each reaction mixture $(\mathrm{pH} 10.0$ ) contained, in $1 \mathrm{ml}, 50 \mu \mathrm{mol}$ sodium carbonate, $50 \mu \mathrm{mol}$ ammonium chloride, $0.4 \mu \mathrm{mol}$ NAD, $100 \mu \mathrm{mol} m y o$-inositol and $100 \mu \mathrm{l}$ cell-free extract. Increase in 
Table 1. Bacterial strains and plasmids used

\begin{tabular}{|c|c|c|}
\hline Strain or plasmid & Relevant characteristics & Reference \\
\hline \multicolumn{3}{|l|}{ Strains } \\
\hline \multicolumn{3}{|l|}{ Escherichia coli } \\
\hline HB101 & supE44 hsdS20 recA13 ara-14 proA2 lacY1 galK2 rpsL20 xyl-5 mtl-1 & Sambrook et al. (1989) \\
\hline \multicolumn{3}{|l|}{ Sinorhizobium meliloti } \\
\hline L5-30 & Wild-type, $\mathrm{Sm}^{\mathrm{R}} \mathrm{Ino}^{+} \mathrm{Mos}^{+} \mathrm{Moc}^{+}$ & Kowalski (1970) \\
\hline 1021 & Wild-type derivative of SU47, $\mathrm{Sm}^{\mathrm{R}} \mathrm{Ino}^{+} \mathrm{Mos}^{-} \mathrm{Moc}^{-}$ & Meade et al. (1982) \\
\hline PC & Wild-type, Ino+ $\mathrm{Mos}^{-} \mathrm{Moc}^{-}$ & Bosworth et al. (1994) \\
\hline RMB7101 & Mutant derived from SU47, $\mathrm{Sm}^{\mathrm{R}} \mathrm{Sp}^{\mathrm{R}} \mathrm{Ino}^{-} \mathrm{Mos}^{-} \mathrm{Moc}^{-}$ & Bosworth et al. (1994) \\
\hline RMB7201 & Mutant derived from $\mathrm{PC}, \mathrm{Sm}^{\mathrm{R}} \mathrm{Sp}^{\mathrm{R}} \mathrm{Ino}^{-} \mathrm{Mos}^{-} \mathrm{Moc}^{-}$ & Bosworth et al. (1994) \\
\hline \#56 & Mutant derived from 1021 , idhA:: $\mathrm{Tn} 5, \mathrm{Km}^{\mathrm{R}} \mathrm{Sm}^{\mathrm{R}} \mathrm{Ino}^{-} \mathrm{Mos}^{-} \mathrm{Moc}^{-}$ & This work \\
\hline L56 & Mutant derived from L5-30, idhA::Tn5, $\mathrm{Km}^{\mathrm{R}} \mathrm{Sm}^{\mathrm{R}} \mathrm{Ino}^{-} \mathrm{Mos}^{+} \mathrm{Moc}^{-}$ & This work \\
\hline \multicolumn{3}{|c|}{ ( } \\
\hline pBluescript KS & $A p^{R}$, cloning vector & Stratagene \\
\hline pLAFR1 & $\mathrm{Tc}^{\mathrm{R}} \mathrm{Mob}^{+} \mathrm{Tra}^{-}$, IncP, cos & Friedman et al. (1982) \\
\hline pRK290 & $\mathrm{Tc}^{\mathrm{R}} \mathrm{Mob}^{+} \mathrm{Tra}^{-}$, IncP & Ditta et al. $(1980)$ \\
\hline pTE3 & $\mathrm{Tc}_{\mathrm{c}}^{\mathrm{R}}$, broad-host-range expression vector, $\operatorname{trp}$ promoter & Egelhoff \& Long (1985) \\
\hline pPM1031 & $\mathrm{Tc}^{\mathrm{R}}$, moc locus of $S$. melilot $i \mathrm{~L} 5-30$ in pLAFR 1 & Murphy et al. (1987) \\
\hline pSR8612 & $\begin{array}{l}\mathrm{Tc}^{\mathrm{R}}, \operatorname{moc} A B C \text { of } S . \text { meliloti } \mathrm{L} 5-30 \text { cloned downstream of the trp promoter } \\
\text { in pTE3 }\end{array}$ & Rossbach et al. (1994b) \\
\hline pMG1000 & $\begin{array}{l}\mathrm{Tc}^{\mathrm{R}} \text {, inositol and arabinose catabolism regions of } S . \text { meliloti } 1021 \text { cloned } \\
\text { into pLAFR } 1\end{array}$ & This work \\
\hline pMG1002 & $\begin{array}{l}\mathrm{Tc}^{\mathrm{R}}, 2.0 \mathrm{~kb} \text { BamHI fragment of pMG1000 cloned into pLAFR1, contains } \\
\text { the idhA gene }\end{array}$ & This work \\
\hline pMG1003 & $\begin{array}{l}\mathrm{Tc}^{\mathrm{R}}, 2.0 \mathrm{~kb} \text { BamHI fragment of pMG1000 cloned into pLAFR } 1 \text {, opposite } \\
\text { orientation as compared to pMG1002 }\end{array}$ & This work \\
\hline pMW184 & $\begin{array}{l}\mathrm{Tc}^{\mathrm{R}}, \text { EcoRI fragment containing } S . \text { meliloti } 1021 \text { ino:: } \mathrm{Tn} 5 \text { region, HpaI } \\
\text { and Bal31 digested, re-ligated with SpeI linker, cloned into pRK290 }\end{array}$ & Williams et al. (1988) \\
\hline pTB6 & $\mathrm{Ap}^{\mathrm{R}}, 590 \mathrm{bp}$ EcoRI-SpeI fragment of pMW184 cloned into pBluescript KS & This work \\
\hline
\end{tabular}

$A_{340}$ was monitored with a Beckman Recording Quartz spectrophotometer. The protein content of cell-free extracts was determined by the method of Lowry. The specific myoinositol dehydrogenase activity was expressed as nmol NADH reduced $\min ^{-1}$ (mg protein $)^{-1} \pm S E M$. The values are the mean of three determinations.

Nodulation assays. Inoculation of alfalfa plants (M. sativa $\mathrm{cv}$. Cardinal) with $S$. meliloti strains was carried out as described previously (Rossbach et al., 1995b).

Rhizopine catabolism assays. Preparation of extracts containing the rhizopine and rhizopine catabolism assays were carried out as described by Rossbach et al. (1994a). Halfstrength minimal $M$ medium without carbon and nitrogen source but mixed 1:1 with nodule extract containing rhizopine was used for the catabolism assays. Rhizopine was detected by high-voltage paper electrophoresis (buffer : $1 \cdot 1 \mathrm{M}$ acetic acid/ $0.7 \mathrm{M}$ formic acid, $\mathrm{pH} \mathrm{1.9)}$ and subsequent alkaline silver staining (Rossbach et al., 1994a).

\section{RESULTS}

\section{S. meliloti mutants unable to catabolize inositol cannot degrade rhizopine}

The ability to utilize the rhizopine 3-O-MSI was originally discovered in S. meliloti strain L5-30 ( $\left.\mathrm{Moc}^{+}\right)$. Many other S. meliloti wild-type strains tested were not able to degrade rhizopine $\left(\mathrm{Moc}^{-}\right.$; Tempé et al., 1982).
Nevertheless, when the rhizopine catabolism (moc) genes were cloned on plasmids and conjugated into $\mathrm{Moc}^{-}$S. meliloti wild-type strains, then these strains were able to catabolize rhizopine (Murphy et al., 1987; Rossbach et al., 1994a). However, when plasmids carrying the moc genes were introduced into a variety of other soil bacteria, these bacteria were found to be unable to degrade rhizopine, suggesting other crucial genes existed in $S$. meliloti contributing to rhizopine degradation. Since rhizopine is an inositol derivative (3O-MSI), we reasoned that inositol catabolism may be involved in rhizopine utilization. Therefore, we studied two S. meliloti mutant strains (RMB7101 and RMB7201) that are unable to use $m y o$-inositol as sole carbon source (Bosworth et al., 1994). Although S. meliloti strains RMB7101 and RMB7201 have different genetic backgrounds, they both carry an $\Omega$ insertion in the inositol catabolism locus (Table 1).

To test the possibility that inositol catabolism plays a crucial role in rhizopine utilization, we introduced plasmids carrying the moc genes (pPM1031 and pSR8612; Table 1), and the vector pLAFR1 into mutant strains RMB7101 and RMB7201, as well as into the corresponding wild-type strains 1021 and PC. The resulting exconjugants were examined for their ability to utilize rhizopine. The moc genes carried by plasmids 
$\begin{array}{lllllllllllll}5 & 1 & 2 & 3 & 4 & 5 & 6 & 7 & 8 & 9 & 10 & 11 & 5\end{array}$

neseselnee

Origin

MOP + MOA

AGR

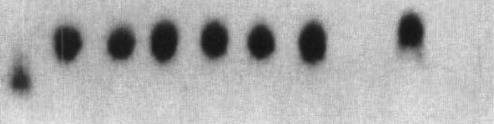

Rhizopine

Fig. 1. High-voltage paper electropherogram of a rhizopine catabolism assay after alkaline silver staining. Half-strength minimal medium was inoculated with different $S$. meliloti strains and incubated for $3 \mathrm{~d}$. Fifteen microlitres of the supernatant of each culture was loaded on the origin of the paper. The cathode is positioned at the bottom of the figure. The reference substances (S) that are loaded in the left and right lanes are mannopine (MOP), mannopinic acid (MOA) and agropine (AGR). Lanes: 1, S. meliloti strain PC(pPM1031); 2, PC(pSR8612); 3, PC(pLAFR1); 4, RMB7201(pPM1031); 5, RMB7201(pSR8612); 6, RMB7201(pLAFR1); 7, RMB7101(pPM1031); 8, RMB7101(pSR8612); 9, RMB7101(pLAFR1); 10, L5$30 ; 11$, uninoculated control (medium with rhizopine).

pPM1031 and pSR8612 were found to be sufficient to confer the ability to utilize rhizopine to the $S$. meliloti wild-type strains PC (Fig. 1, lanes 1 and 2) and 1021 (data not shown). However, mutant strains RMB7101 and RMB7201 harbouring these plasmids were found to be unable to utilize rhizopine (Fig. 1, lanes 4, 5, 7 and 8).
As expected, the control plasmid pLAFR1 could not confer the ability to degrade rhizopine to these strains (Fig. 1, lanes 3, 6 and 9). The catabolism assay with wild-type strain PC harbouring plasmid PLAFR1 shows an apparent shift in mobility of the rhizopine spot on the electropherogram (Fig. 1, lane 3). This minor mobility shift is usually observed in catabolism assays with rhizobial Moc ${ }^{-}$strains (Rossbach et al., 1994a, 1995b), but it is not displayed by other $\mathrm{Moc}^{-}$soil bacteria ( $\mathrm{S}$. Rossbach, unpublished observations) or by the mutant strains that are unable to catabolize myo-inositol (Fig. 1, lanes 4-9). The reasons for the observed mobility shift are not entirely clear; it could be that the $\mathrm{Moc}^{-}$rhizobial strains are able to partially degrade the rhizopine, but at this point the chemical structure of the intermediates in the rhizopine catabolic pathway is not known. Nevertheless, the catabolism assays carried out with the mutant strains unable to catabolize myo-inositol show that these strains are also unable to degrade the rhizopine. Thus, we conclude from these experiments that a functional inositol catabolism pathway is necessary for the ability to utilize rhizopine in S. meliloti.

\section{Cloning of the inositol locus from S. meliloti 1021}

For the construction of mutant strains RMB7101 and RMB7201, the genomic region surrounding a transposon insertion in an inositol catabolism region of $S$. meliloti 1021 had been cloned on plasmid pMW184 (Bosworth et al., 1994; Williams et al., 1988). This mutated DNA region had been further manipulated with exonuclease Bal31 (Williams et al., 1988). Thus, the mutated region could not serve as source of the wildtype genomic region; however, it could serve as a hybridization probe. A subclone of pMW184, pTB6 (Table 1; Fig. 2), carries genomic DNA adjacent to the

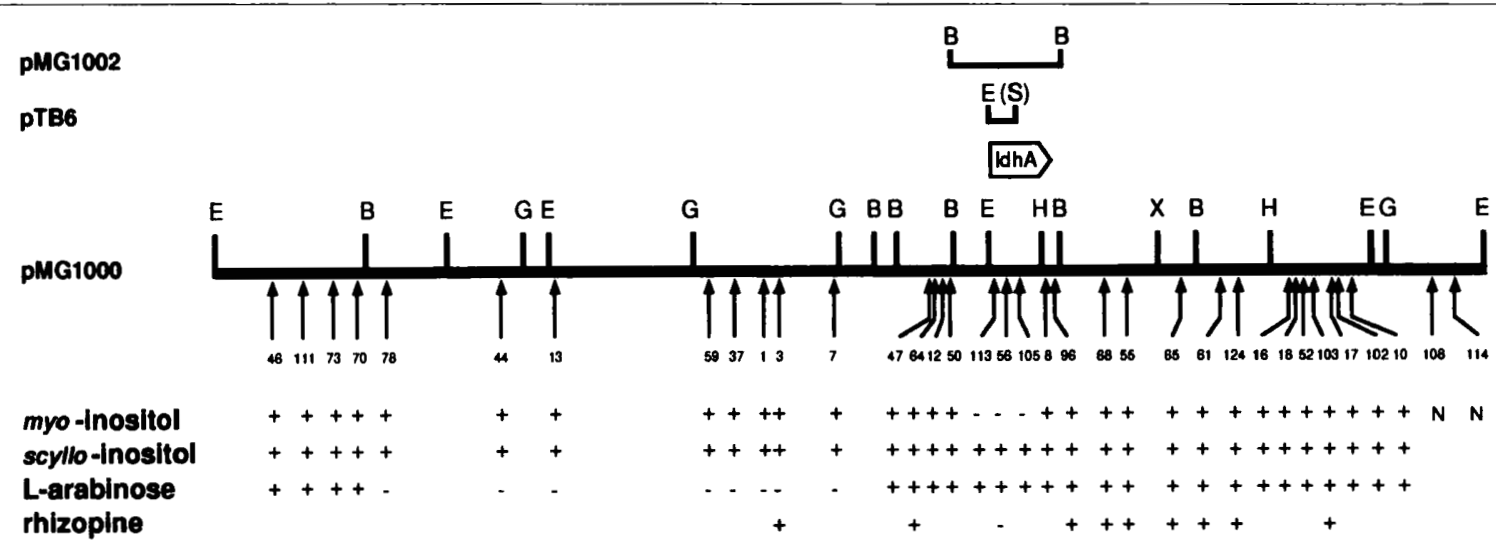

Fig. 2. Correlated physical and genetic map of the inositol locus of S. meliloti 1021. The DNA fragments cloned in pMG1000, pMG1002 and pTB6 are shown. B, BamHI; G, BgllI; E, EcoRI; H, HindllI; X, Xbal. (S), Spel linker present in pTB6. The boxed arrow denotes the location and direction of the idhA gene. The numbered arrows denote the different locations of the transposon Tn5 insertions in pMG1000. The phenotypes of the S. meliloti mutant strains that resulted from the gene-replacement experiment are indicated on the bottom: $N$, no successful marker exchange; + , able to catabolize carbon source; -, unable to catabolize carbon source. Before determining the rhizopine catabolism phenotype, plasmid pPM1031 carrying the moc genes was conjugated into the different mutant strains. 
original transposon insertion of the inositol locus on a $490 \mathrm{bp}$ EcoRI-Spel fragment. We used this fragment as a probe to clone the corresponding wild-type genomic inositol catabolism locus. A colony hybridization experiment was performed using the cosmid library of $S$. meliloti 1021 constructed in the vector pLAFR1 (de Bruijn et al., 1989). Twelve hundred colonies of the clone bank were transferred onto nylon filters and hybridized with the above-mentioned probe. Seven colonies were identified that yielded positive hybridization signals. Plasmid DNA of these seven colonies was isolated, digested with the restriction endonuclease EcoRI, separated by agarose gel electrophoresis and blotted onto nylon filters. As a control, $S$. meliloti total chromosomal DNA restricted with EcoRI was included. The blot was hybridized with the $490 \mathrm{bp}$ EcoRI-Spel fragment of pTB6, and one of the cosmid clones (pMG1000) was found to contain a hybridizing fragment of $7 \mathrm{~kb}$. A fragment of the same size in the lane loaded with S. meliloti 1021 wild-type DNA also hybridized with this probe (data not shown).

\section{Complementation of mutant strains unable to catabolize myo-inositol}

To verify that pMG1000 indeed carries the inositol catabolism locus, we conjugated pMG1000 into $S$. meliloti strains RMB7101 and RMB7201. The resulting strains were examined for growth on minimal $M$ medium with $0.2 \%$ myo-inositol as sole carbon source. Strains RMB7101 and RMB7201 containing plasmid pMG1000 were able to grow on minimal medium with myo-inositol as sole carbon source, whereas RMB7101 and RMB7201 containing the vector pLAFR1 were not.

Strains of E. coli are unable to degrade myo-inositol (Holt, 1993). To examine whether pMG1000 could also confer the ability to use inositol as sole carbon source to E. coli, strain HB101 was transformed with pMG1000 and its growth on minimal M9 medium with myoinositol as sole carbon source was tested. Strain HB101 harbouring pMG1000 was found to be able to grow on minimal M9 medium with glucose as sole carbon source, but unable to grow on M9 medium with $0.2 \%$ myoinositol medium as sole carbon source. Thus, the $S$. meliloti genetic region carried by pMG1000 appears to be insufficient to confer the ability to use myo-inositol as sole carbon or energy source upon E. coli.

\section{Construction of a correlated physical and genetic map of the S. meliloti DNA carried by PMG1000 via transposon Tn 5 mutagenesis}

In addition to the $7.0 \mathrm{~kb} E c o \mathrm{RI}$ fragment that hybridized with the $490 \mathrm{bp} \mathrm{EcoRI-SpeI} \mathrm{fragment} \mathrm{of} \mathrm{pTB6,} \mathrm{plasmid}$ pMG1000 carries four additional EcoRI fragments of $\sim 8.1,4.3,2.05$ and $1.95 \mathrm{~kb}$. To delimit the genetic locus responsible for inositol catabolism, we subjected pMG1000 to Tn5 mutagenesis (de Bruijn \& Rossbach, 1994). Fifty out of 120 independent $\operatorname{Tn} 5$ insertions were mapped to the DNA segment cloned in pMG1000 (see Fig. 2). Using restriction digests with the endonucleases
HindIII, BglII and BamHI, these 50 insertions were more precisely mapped to 35 different sites (Fig. 2). To determine the phenotype of these $\operatorname{Tn} 5$ insertion mutants, we replaced the wild-type region of $S$. meliloti strain 1021 with the different pMG1000: : Tn5-containing fragments. All resulting mutant strains were tested for their growth on minimal medium with myo-inositol as sole carbon and energy source. Only mutant strains \#56, \#105 and \#113 were found to be unable to utilize myoinositol as sole carbon and energy source. The corresponding $\operatorname{Tn} 5$ insertions were located in a $1 \mathrm{~kb}$ region of the $7 \mathrm{~kb} E c o$ RI fragment previously found to hybridize with the $490 \mathrm{bp}$ EcoRI-Spel fragment of pTB6. The ability of the mutant strains to grow on a variety of different carbon sources, including scyllo-inositol, sorbitol, mannitol, adonitol, D-glucose, fructose, L-arabinose, D-mannose and succinate, was also examined. All mutant strains (and the wild-type) were found to be capable of utilizing these compounds as sole carbon and energy source, with only one exception. Mutant strains $\# 1,3,7,13,37,44,59$ and 78 were found to grow very poorly on L-arabinose as sole carbon source. These mutants map to a $9 \mathrm{~kb}$ region, $3 \mathrm{~kb}$ upstream from the inositol locus (Fig. 2). This $9 \mathrm{~kb}$ region may, therefore, carry a genetic locus directly or indirectly involved in Larabinose utilization.

\section{Rhizopine utilization phenotype of the S. meliloti mutant strains}

To examine which areas of the $S$. meliloti region carried by pMG1000 were involved in rhizopine catabolism, we introduced plasmid pPM1031 into mutant strains \#3, $55,56,61,64,65,68,96,103$ and 124 . The resulting transconjugants were examined for rhizopine utilization. Strain \#56(pPM1031) was found to be the only one unable to utilize rhizopine.

\section{Construction of an S. meliloti L5-30 strain unable to degrade myo-inositol}

S. meliloti mutant strains unable to degrade myoinositol were found to be unable to utilize rhizopine, when provided with the moc genes in trans (see above). To show that the same applied to the $S$. meliloti strain from which the moc genes were isolated (strain L5-30), we performed a gene-replacement experiment with strain L5-30 and the transposon-mutated inositol region of $S$. meliloti 1021. Plasmid pMG1000::56 was used for this 'heterologous' gene replacement experiment and gene exchange in strain L5-30 was verified by Southern blotting. The resulting strain, L56, was found to be unable to use myo-inositol as sole carbon source or to utilize rhizopine (data not shown).

\section{Subcloning of the region carrying the inositol catabolism region}

To further delimit the region conferring the ability to degrade inositol, we constructed a pLAFR1 plasmid derivative carrying a $2.0 \mathrm{~kb} B a m \mathrm{HI}$ fragment from 
RmIdhA

BsYrbE

BsYucG

SgStrI

RMMOCA

BsIolG

RmIdhA

BsYrbE

BsYucG

SgstrI

RMMOCA

BsIolG

RmIdhA

BgYrbE

BsYUCG

SgStrI

ImMOCA

BsIolG

RmIdhA

BsYrbE

BsYucG

SgStrI

RmMocA

Bs I01G

RmIdhA

BsYrbE

BsYucG

SgStrI

RMMOcA

BsIolG

RmIdhA

BsYrbE

BsYucG

SgStrI

RMMOCA

Bs IolG

RmIdhA

BsYrbE

BsYucG

sgstrI

BsIolG

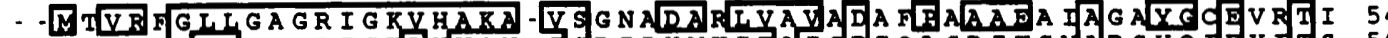

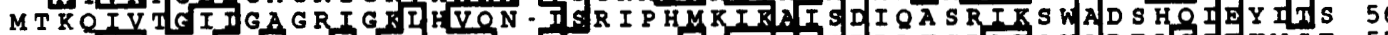

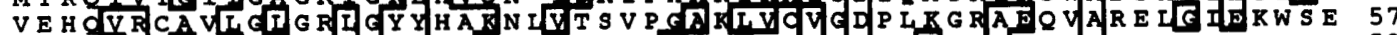
... MTR F I GIVGAGRM COVHVRAAAES L VEIAAVADPIAASRTNLAGNGITTYETAG 56

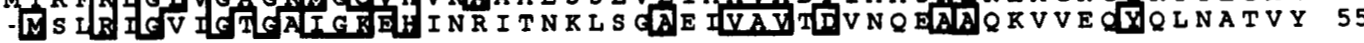

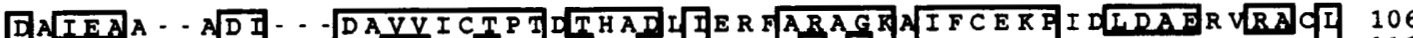

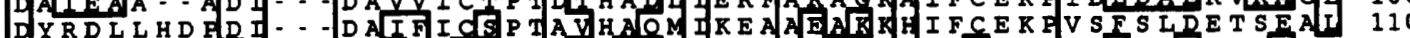

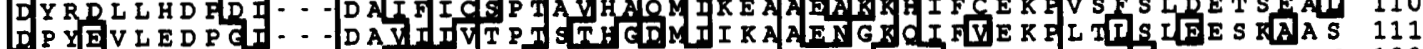

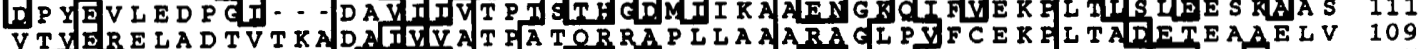

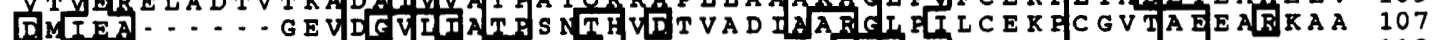
PNDDSLLADE- NVIDAVLVTSWG PAHESSVIKA I KACKYVFCEKALAT IABGCMRIV 110

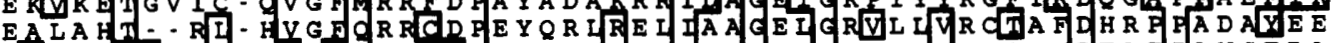

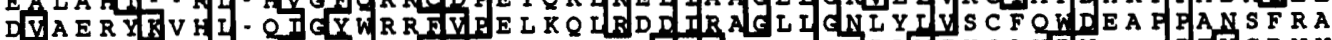

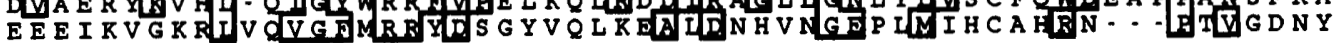

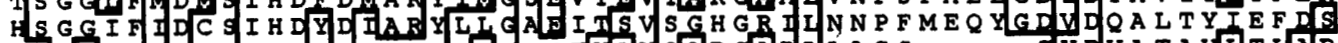

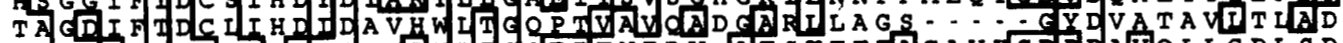

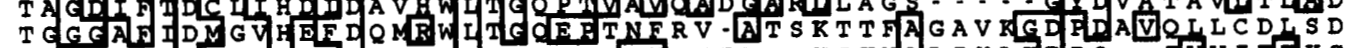

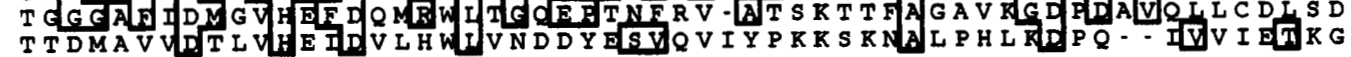

Fig. 3. Comparison of the deduced amino acid sequences of the $S$. meliloti myo-inositol dehydrogenase gene (RmldhA; GenBank accession no. Af059313), the B. subtilis yrbE and yucG genes (BsYrbE, accession no. Z99118; BsYucG, accession no. Z93940), the Str. griseus strl gene (SgStrl, accession no. Y00459), the S. meliloti mocA gene (RmMocA, accession no. $\mathrm{X78503)}$ and the $B$. subtilis io/G gene (BslolG, accession no. M76431). The alignment was created by using the programs PILEUP and SeqVu. Amino acids identical to the amino acids in the inositol dehydrogenase sequence of $S$. meliloti are boxed. The numbers of the amino acid residues are shown on the left and right.

pMG1000 in both orientations, resulting in plasmids pMG1002 and pMG1003 (Table 1). Both plasmids were introduced into $S$. meliloti strain \#56 and their ability to complement this mutant strain was examined. Both plasmids pMG1002 and pMG1003 could confer the ability to use myo-inositol as sole carbon and energy source upon mutant strain \#56, suggesting that an entire inositol degradation gene was present on this $2 \mathrm{~kb}$ BamHI fragment.

\section{Determination of the DNA sequence of the myo- inositol dehydrogenase (idhA) gene}

To further characterize the myo-inositol degradation gene, the DNA sequence of a 1200 bp region starting $96 \mathrm{bp}$ upstream of the EcoRI site of plasmid pMG1002 was determined. The analysis of the resulting DNA sequence using the CodonUse program by $\mathrm{C}$. Halling (see Methods) predicted the presence of a 993-bp-long ORF. A putative ribosome-binding site (AAGGA) was found to be located $8 \mathrm{bp}$ upstream of the presumptive ATG start codon. Twenty-four base pairs downstream of the stop codon of the predicted ORF, a region of dyad symmetry was found with the potential to form a stem-loop (terminator) structure. The predicted ORF encodes a protein of 330 amino acids. The deduced protein has a predicted molecular mass of $35130 \mathrm{Da}$ and a pI of $5 \cdot 34$. The deduced amino acid sequence was submitted to a database search and was found to share high similarity with the deduced protein sequences of the $B$. subtilis $y r b E$ ( $42 \%$ identity, $53 \%$ similarity), $B$. subtilis yucG ( $38 \%$ identity, $47 \%$ similarity), Streptomyces griseus strI ( $32 \%$ identity, $42 \%$ similarity), $S$. meliloti mocA (33\% identity, $40 \%$ similarity) and $B$. subtilis iolG (formerly idh) ( $28 \%$ identity, $40 \%$ similarity) genes (Fig. 3). The yrbE (accession no. Z99118) 
and yucG (accession no. Z93940) genes represent ORFs with unknown functions originating from the B. subtilis complete genome sequencing project (Kunst et al., 1997), whereas the B. subtilis iolG gene encodes a myo-inositol dehydrogenase (Fujita et al., 1991; Yoshida et al., 1997). The Str. griseus strI gene is a gene of unknown function located in the operon for the biosynthesis of streptomycin, an inosamine derivative (Mansouri \& Piepersberg, 1991). The mocA gene product of $S$. meliloti L5-30 is essential for rhizopine utilization (Rossbach et al., 1994a). Common to all these sequences is an $\mathrm{N}$ terminal $\mathrm{NAD}(\mathrm{H})$-binding motif, consisting of the amino acids GXGXXG, which has been proposed to form a $\beta \alpha \beta$-fold involved in binding the ADP moiety of $N A D(H)$ in dehydrogenases (Thompson \& Donkersloot, 1992). Thus, we conclude that these genes potentially all encode $\mathrm{NAD}(\mathrm{H})$-dependent dehydrogenases, similar to the B. subtilis iol $G$ gene that encodes a functional myo-inositol dehydrogenase (Fujita et al., 1991; Yoshida et al., 1997).

\section{Determination of the myo-inositol dehydrogenase activity}

To examine whether the ORF found on plasmid pMG1000 and its derivatives indeed encodes an enzyme with myo-inositol dehydrogenase activity, an enzyme assay was carried out. $S$. meliloti wild-type and mutant strains were grown in minimal medium with $0.2 \%$ succinate as carbon source and $0.02 \%$ myo-inositol. $S$. meliloti strain 1021 harbouring the pLAFR1 vector was found to display a specific myo-inositol dehydrogenase activity of $62 \pm 3 \mathrm{nmol} \mathrm{NADH}$ reduced $\mathrm{min}^{-1}(\mathrm{mg}$ protein $)^{-1}$. Strain 1021 harbouring pMG1000, however, displayed a four times higher specific myo-inositol dehydrogenase activity $255 \pm 19 \mathrm{nmol} \mathrm{NADH}$ reduced $\min ^{-1}$ (mg protein $)^{-1}$ ]. Mutant strain \#56 did not display any detectable myo-inositol dehydrogenase activity, but when it harboured plasmid pMG1000 it displayed enzyme activity comparable to the wild-type strain containing pMG1000 $[241 \pm 5 \mathrm{nmol} N \mathrm{NADH}$ reduced $\mathrm{min}^{-1}$ (mg protein) ${ }^{-1}$ ]. Moreover, mutant strain L56 displayed no detectable myo-inositol dehydrogenase activity, whereas its corresponding wild-type strain L530 displayed a myo-inositol dehydrogenase activity of $25 \pm 2 \mathrm{nmol} \mathrm{NADH}$ reduced $\mathrm{min}^{-1}$ (mg protein) ${ }^{-1}$. No myo-inositol dehydrogenase activity could be observed when the wild-type strains were grown in medium without $0.02 \%$ myo-inositol, suggesting that the myoinositol dehydrogenase activity is inducible in S. meliloti.

\section{Nodulation and nitrogen-fixation phenotype of myo- inositol degradation mutants}

Mutant $S$. meliloti strains \#56 and L56 could nodulate $M$. sativa plants and induce pink, nitrogen-fixing nodules on alfalfa indistinguishable from those induced by wild-type strains. These observations confirm that the myo-inositol dehydrogenase gene of $S$. melilot $i$ is not essential for the establishment of an effective nitrogenfixing symbiosis.

\section{DISCUSSION}

Inositol derivatives are commonly found in legume nodules. For example, in soybean nodules, myo-inositol, D-chiro-inositol, 3-O-methyl-D-chiro-inositol (Dpinitol) and 4-O-methyl-myo-inositol (ononitol) have been found to be the most abundant water-soluble forms of carbon in bacteroids (Streeter, 1987). Ononitol has also been found to be the major soluble carbohydrate in pea nodules induced by $R$. leguminosarum (Scot \& Egsgaard, 1984). However, the role of different cyclitol compounds in nitrogen-fixing symbioses is not fully understood. Some of the methyl ethers of inositol increase in plant tissues during salt or water stress (Loewus et al., 1990), leading to the hypothesis that perhaps bacteroids in the nodule are subjected to high osmotic pressure and thus synthesize cyclitol compounds as osmotic protectants.

However, a different role has been assigned to unusual compounds such as the rhizopine 3-O-MSI. It has been postulated that rhizopine plays a role in enhancing the competitiveness of $S$. meliloti strains that are able to synthesize 3-O-MSI during infection of their host, alfalfa, by being able to catabolize it in the nodule or under free-living conditions (Murphy \& Saint, 1992; Rossbach et al., 1995a). The hypothesis underlying this concept is that the 3-O-MSI synthesized in nodules is secreted into the rhizosphere and serves as a nutrient source for the strains that are able to catabolize it. For example, strains with the ability to utilize rhizopine are able to nodulate plants at a higher rate (Gordon et al., 1996), and mutant strains unable to catabolize rhizopine are less competitive with respect to nodule occupancy (Rossbach et al., 1995a).

Here, we report that a functional myo-inositol catabolism pathway is essential for the ability of $S$. meliloti to utilize rhizopine. To prove the connection between myo-inositol catabolism and rhizopine utilization, we made use of $S$. meliloti mutants unable to use myoinositol as sole carbon source, and demonstrated that these mutant strains were unable to catabolize rhizopine. We further delimited the region responsible for this phenotype to a DNA fragment of $2 \mathrm{~kb}$, harbouring an ORF, the predicted product of which shares significant amino acid similarity with the myo-inositol dehydrogenase encoded by the iolG (idh) gene of B. subtilis. Moreover, enzyme assays of strains carrying a mutation in this gene revealed that these strains were deficient in myo-inositol dehydrogenase activity. Thus, we conclude that the $i d h A$ gene of $S$. meliloti encodes a functional myo-inositol dehydrogenase.

Based on the analysis of the phenotype of the idh mutant strains \#56, \#105 and \#113, which were able to utilize scyllo-inositol as sole carbon source, we conclude that the $S$. meliloti myo-inositol dehydrogenase does not play an essential role in the degradation of scyllo-inositol. Therefore, it seems that the activity of the myo-inositol dehydrogenase is specific for the myo-stereoisomer of inositol. This conclusion is supported by the observation that the purified myo-inositol dehydrogenase enzyme of 
B. subtilis reacts only with myo-inositol as substrate, and not with scyllo-inositol (Ramaley et al., 1979).

The results described in this paper reveal that myoinositol dehydrogenase is essential for rhizopine utilization, suggesting that myo-inositol is an intermediate in rhizopine catabolism. It has also been speculated that scyllo-inosamine might be an intermediate during catabolism of rhizopine (Murphy et al., 1987). It is possible that both compounds, scylloinosamine and myo-inositol, are intermediates in the rhizopine catabolic pathway; however, the exact structure of the degradation products of rhizopine is not known yet, mainly because of the unavailability of chemically synthesized 3-O-MSI.

Whereas the exact pathway of rhizopine degradation remains to be elucidated, the pathway of myo-inositol degradation, however, has been studied in detail in $A$. aerogenes (now K. pneumoniae; Anderson \& Magasanik, 1971a, b; Berman \& Magasanik, 1966a, b). In these publications, Magasanik and others have shown that this organism catabolizes myo-inositol via the intermediates 2-keto-myo-inositol, D-2,3-diketo-4deoxy-epi-inositol, 2-deoxy-5-keto-D-gluconic acid and 2-deoxy-5-keto-D-gluconic acid 6-phosphate, resulting in dihydroxyacetone phosphate and malonic semialdehyde. Malonic semialdehyde is further degraded by malonic semialdehyde carboxylase to acetyl-CoA, $\mathrm{CO}_{2}$ and $\mathrm{NADH}+\mathrm{H}^{+}$. Poole et al. (1994) have described two enzymes that are involved in the degradation of myo-inositol in $R$. leguminosarum bv. viciae, myo-inositol dehydrogenase and 2-keto-myo-inositol dehydratase. Based on enzyme assay data, Poole $e t$ al. (1994) have postulated that the degradation of myoinositol in $R$. leguminosarum bv. viciae follows a pathway similar to the one described for K. pneumoniae.

In fact, B. subtilis is the only micro-organism from which the inositol dehydrogenase enzyme has been purified and the corresponding gene has been cloned (Fujita et al., 1991; Ramaley et al., 1979). It is interesting to note that the deduced gene product of the idhA gene of $S$. meliloti not only shows similarities to the deduced protein product of the $B$. subtilis iolG (idb) gene, but also to the deduced protein products of $y r b E$ and $y u c G$ in B. subtilis (Kunst et al., 1997). However, it is not known whether the $y u c G$ or $y r b E$ gene products play a role in inositol catabolism.

Another interesting observation is the similarity of the $S$. meliloti idhA gene product with the product of the $S$. meliloti mocA gene. MocA is essential for rhizopine degradation as well (Rossbach et al., 1994a). MocA and IdhA display $33 \%$ identity in their amino acid sequence and both show signatures of dehydrogenases, suggesting that they could carry out related functions. However, despite their similarities at the amino acid level, these two gene products cannot replace each other's function. On the one hand, the mocA gene could not complement the idhA mutant \#56 (S. Rossbach \& M. Galbraith, unpublished observation), and on the other hand, the mocA mutant unable to utilize rhizopine was generated in a strain carrying the idh wild-type gene (Rossbach et al., 1994a).

It is also interesting to note that the idhA gene in $S$. meliloti does not seem to be part of a larger operon involved in myo-inositol degradation. All S. meliloti mutant strains carrying insertions in the vicinity of the idhA gene were found to be able to utilize myo-inositol as sole carbon source. This is in contrast to observations made in B. subtilis, in which the iolG gene is part of an 11-kb-long operon with 12 different genes (Yoshida et al., 1994, 1997). Ten of these genes are essential for inositol catabolism, since $B$. subtilis strains with mutations in these genes have been said to be unable to degrade myo-inositol as sole carbon source (Yoshida $e t$ al., 1997). The results from our experiments do not exclude the presence of other genes essential for myoinositol degradation elsewhere in the genome of $S$. meliloti.

Clearly, both degradative pathways for myo-inositol and rhizopine in $S$. meliloti need further study. Interestingly, Scupham et al. (1996) have reported that $S$. meliloti strains with $\Omega$ insertions in the inositol locus increase alfalfa yield in field tests. Moreover, since we have shown here that myo-inositol catabolism is essential for rhizopine catabolism, further studies on the $S$. meliloti inositol catabolism pathway are clearly warranted and are likely to provide major insights into the molecular microbial ecology of symbiotic plantmicrobe interactions.

\section{ACKNOWLEDGEMENTS}

We would like to thank Dr Rob Eversole and Uwe Rossbach for help with preparing the figures, and Janeen Holmes for help with the manuscript. This work was funded by the College of Arts and Sciences and the Center for Research into Environmental Signal Transduction (CREST) at Western Michigan University, and at Michigan State University by the US Department of Energy DE-FG02-91ER20021 and the US Department of Agriculture (92-39210-8224).

\section{REFERENCES}

Altschul, S. F., Gish, W., Miller, W., Myers, E. W. \& Lipman, D. J. (1990). Basic local alignment search tool. J Mol Biol 21 5, 403-410.

Anderson, W. A. \& Magasanik, B. (1971a). The pathway of myoinositol degradation in Aerobacter aerogenes - identification of the intermediate 2-deoxy-5-keto-D-gluconic acid. J Biol Chem 246, 5653-5661.

Anderson, W. A. \& Magasanik, B. (1971b). The pathway of myoinositol degradation in Aerobacter aerogenes - conversion of 2deoxy-5-keto-D-gluconic acid to glycolytic intermediates. $J$ Biol Chem 246, 5662-5675.

Ausubel, F. M., Brent, R., Kingston, R. E., Moore, D. D., Seidman, J. G., Smith, J. A. \& Struhl, K. (1992). Short Protocols in Molecular Biology. New York: Wiley.

Beringer, J. E. (1974). $\mathrm{R}$ factor transfer in Rhizobium leguminosarum. J Gen Microbiol 84, 188-198.

Berman, T. \& Magasanik, B. (1966a). The pathway of myoinositol degradation in Aerobacter aerogenes - dehydrogenation and dehydration. J Biol Chem 241, 800-806.

Berman, T. \& Magasanik, B. (1966b). The pathway of myo- 
inositol degradation in Aerobacter aerogenes-ring scission. $J$ Biol Chem 241, 807-812.

Bosworth, A. H., Williams, M. K., Albrecht, K. A. \& 7 other authors (1994). Alfalfa yield response to inoculation with recombinant strains of Rhizobium meliloti with an extra copy of $\operatorname{dct} A B C$ and/or modified nifA expression. Appl Environ Microbiol 60, 3815-3832.

de Bruijn, F. J. \& Rossbach, S. (1994). Transposon mutagenesis. In Methods for General and Molecular Bacteriology, pp. 387-405. Edited by P. Gerhardt, R. G. E. Murray, W. A. Wood \& N. R. Krieg. Washington, DC: American Society for Microbiology.

de Bruijn, F. J., Rossbach, S., Schneider, M., Ratet, P., Messmer, S., Szeto, W., Ausubel, F. M. \& Schell, J. (1989). Rhizobium meliloti 1021 has three differentially regulated loci involved in glutamine biosynthesis, none of which is essential for symbiotic nitrogen fixation. J Bacteriol 171, 1673-1682.

Ditta, G., Stanfield, S., Corbin, D. \& Helinski, D. R. (1980). Broad host range DNA cloning system for Gram-negative bacteria: construction of a gene bank of Rhizobium meliloti. Proc Natl Acad Sci USA 77, 7347-7351.

Egelhoff, T. T. \& Long, S. R. (1985). R hizobium meliloti nodulation genes: identification of nodDABC gene products, purification of nodA protein and expression of $\operatorname{nodA}$ in Rhizobium meliloti. J Bacteriol 164, 591-599.

Friedman, A. M., Long, S. R., Brown, S. E., Buikema, W. J. \& Ausubel, F. M. (1982). Construction of a broad host range cloning vector and its use in the genetic analysis of Rhizobium mutants. Gene 18, 289-296.

Fujita, Y., Shindo, K., Miwa, Y. \& Yoshida, K. (1991). Bacillus subtilis inositol dehydrogenase-encoding gene $(i d h)$ : sequence and expression in Escherichia coli. Gene 108, 121-125.

Gordon, D. M., Ryder, M. H., Heinrich, K. H. \& Murphy, P. J. (1996). An experimental test of the rhizopine concept in $\mathrm{R} h \mathrm{~h}$ zobium meliloti. Appl Environ Microbiol 62, 3991-3996.

Holt, J. G. (1993). Bergey's Manual of Determinative Bacteriology. Baltimore, MD: Williams \& Wilkins.

Kiss, G. B., Vincze, E., Kalman, Z., Forrai, T. \& Kondorosi, A. (1979). Genetic and biochemical analysis of mutants affected in nitrate reduction in Rhizobium meliloti. J Gen Microbiol 113, 105-118.

Kowalski, M. (1970). Transducing phages of Rhizobium meliloti. Acta Microbiol Pol Ser A 19, 109-114.

Kunst, F., Ogasawaka, N., Mozer, I. \& 148 others (1997). The complete genome sequence of the Gram-positive bacterium Bacillus subtilis. Nature 390, 249-256.

Loewus, F. A. (1990). Structure and occurrence of inositols in plants. In Inositol Metabolism in Plants, pp. 1-11. Edited by D. J. Morre, W. F. Boss \& F. A. Loewus. New York: Wiley-Liss. Loewus, F. A., Everard, J. D. \& Young, K. A. (1990). Inositol metabolism: precursor role and breakdown. In Inositol Metabolism in Plants, pp. 21-45. Edited by D. J. Morre, W. F. Boss \& F. A. Loewus. New York: Wiley-Liss.

Mansouri, K. \& Piepersberg, W. (1991). Genetics of streptomycin production in Streptomyces griseus: nucleotide sequence of five genes, strFGHIK, including a phosphatase gene. Mol Gen Genet 228, 459-469.

Meade, H. M., Long, S. R., Ruvkun, G. B., Brown, S. E. \& Ausubel, F. M. (1982). Physical and genetic characterization of symbiotic and auxotrophic mutants of Rhizobium meliloti induced by transposon Tn5 mutagenesis. J Bacteriol 149, 114-122.

Miller, J. H. (1992). A Short Course in Bacterial Genetics. Cold Spring Harbor, NY: Cold Spring Harbor Laboratory.
Murphy, P. J. \& Saint, C. P. (1992). Rhizopines in the legume-Rhizobium symbiosis. In Molecular Signals in PlantMicrobe Communication, pp. 377-390. Edited by D. P. S. Verma. Boca Raton, FL: CRC Press.

Murphy, P. J., Heycke, N., Banfalvi, Z., Tate, M. E., de Bruijn, F. J., Kondorosi, A., Tempé, J. \& Schell, J. (1987). Genes for the catabolism and synthesis of an opine-like compound in Rhizobium meliloti are closely linked and on the Sym plasmid. Proc Natl Acad Sci USA 84, 493-497.

Murphy, P. J., Heycke, N., Trenz, S. P., Ratet, P., de Bruijn, F. J. \& Schell, J. (1988). Synthesis of an opine-like compound, a rhizopine, in alfalfa nodules is symbiotically regulated. Proc Natl Acad Sci USA 85, 9133-9137.

Murphy, P. J., Trenz, S. P., Grzemski, W., de Bruijn, F. J. \& Schell, J. (1993). The Rhizobium meliloti rhizopine mos locus is a mosaic structure facilitating its symbiotic regulation. J Bacteriol $\mathbf{1 7 5}$, 5193-5204.

Poole, P. S., Blyth, A., Reid, C. J. \& Walters, K. (1994). myoInositol catabolism and catabolite regulation in Rhizobium leguminosarum bv. viciae. Microbiology 140, 2787-2795.

Ramaley, R., Fujita, Y. \& Freese, E. (1979). Purification and properties of Bacillus subtilis inositol dehydrogenase. J Biol Chem 254, 7684-7690.

Rossbach, S., Kulpa, D. A., Rossbach, U. \& de Bruijn, F. J. (1994a). Molecular and genetic characterization of the rhizopine catabolism (mocABCR) genes of Rhizobium meliloti L5-30. Mol Gen Genet 245, 11-24.

Rossbach, S., McSpadden, B., Kulpa, D. \& de Bruijn, F. J. (1994b). Rhizopine synthesis and catabolism genes for the creation of 'biased rhizospheres' and a marker system to detect (genetically modified) microorganisms in the soil. In Biotechnology Risk Assessment, pp. 223-244. Edited by M. Levin, C. Grim \& J. S. Angle. College Park, MD: University of Maryland Biotechnology Institute.

Rossbach, S., McSpadden, B., Ganoff, M. \& de Bruijn, F. J. (1995a). Rhizobium meliloti rhizopine catabolism genes: distribution, role in competition and potential as marker gene to track microbes. In Biotechnology Risk Assessment, pp. 180-188. Edited by $\mathrm{M}$. Levin, C. Grim \& J. S. Angle. College Park, MD: University of Maryland Biotechnology Institute.

Rossbach, S., Rasul, G., Schneider, M., Eardly, B. \& de Bruijn, F. J. (1995b). Structural and functional conservation of the rhizopine catabolism $(m o c)$ locus is limited to selected Rhizobium meliloti strains and unrelated to their geographical origin. Mol PlantMicrobe Interact 8, 549-559.

Sambrook, J., Fritsch, E. F. \& Maniatis, T. (1989). Molecular Cloning: a Laboratory Manual, 2nd edn. Cold Spring Harbor, NY: Cold Spring Harbor Laboratory.

Scot, L. \& Egsgaard, H. (1984). Identification of ononitol and Omethyl-scyllo-inositol in pea nodules. Planta 161, 32-36.

Scupham, A. J., Bosworth, A. H., Ellis, W. R., Wacek, T. J., Albrecht, K. A. \& Triplett, E.W. (1996). Inoculation with Sinorhizobium meliloti RMBPC-2 increases alfalfa yield compared with inoculation with a nonengineered wild-type strain. Appl Environ Microbiol 62, 4260-4262.

Streeter, J. G. (1987). Carbohydrate, organic acid, and amino acid composition of bacteroids and cytosol from soybean nodules. Plant Physiol 85, 768-773.

Tempé, J., Petit, A. \& Bannerot, H. (1982). Presence de substances semblables a des opines dans des nodosites de luzerne. $C R$ Acad Sci Paris Ser III 295, 413-426.

Thompson, J. \& Donkersloot, J. A. (1992). N-(carboxyalkyl) 
amino acids: occurrence, synthesis, and functions. Annu Rev Biochem 61, 517-557.

Wexler, M., Gordon, D. M. \& Murphy, P. J. (1995). The distribution of inositol rhizopine genes in Rhizobium populations. Soil Biol Biochem 27, 531-537.

Williams, M. K., Cannon, F., Mclean, P. \& Beynon, J. (1988). Vector for the integration of genes into a defined site in the Rhizobium meliloti genome. In Molecular Genetics of PlantMicrobe Interactions, pp. 198-199. Edited by R. Palacios \& D. P. S. Verma. St Paul, MN: American Phytopathological Society.
Yoshida, K., Sano, H., Miwa, Y., Ogasawara, N. \& Fujita, Y. (1994). Cloning and nucleotide sequencing of a $15 \mathrm{~kb}$ region of the Bacillus subtilis genome containing the iol operon. Microbiology 140, 2289-2298.

Yoshida, K. I., Aoyama, D., Ishio, I., Shibayama, T. \& Fujita, Y. (1997). Organization and transcription of the myo-inositol operon, iol, of Bacillus subtilis. J Bacteriol 179, 4591-4598.

Received 14 April 1998; revised 22 June 1998; accepted 26 June 1998. 